Copyright (C) 2015 by the author(s). Published here under license by the Resilience Alliance.

Mitchell, M. G. E., E. M. Bennett, A. Gonzalez, M. J. Lechowicz, J. M. Rhemtulla, J. A. Cardille, K. Vanderheyden, G. Poirier-Ghys, D. Renard, S. Delmotte, C. H. Albert, B. Rayfield, M. Dumitru, H.-H. Huang, M. Larouche, K. N. Liss, D. Y. Maguire, K. T.

Martins, M. Terrado, C. Ziter, L. Taliana, and K. Dancose. 2015. The Montérégie Connection: linking landscapes, biodiversity, and ecosystem services to improve decision making. Ecology and Society 20(4):15. http://dx.doi.org/10.5751/ES-07927-200415

Research, part of a Special Feature on Programme on Ecosystem Change and Society (PECS): Knowledge for Sustainable Stewardship of Social-ecological Systems

\title{
The Montérégie Connection: linking landscapes, biodiversity, and ecosystem services to improve decision making
}

\author{
Matthew G. E. Mitchell ${ }^{1,2,3}$, Elena M. Bennett ${ }^{1,4}$ Andrew Gonzalez $^{2,5}$, Martin J. Lechowicz $^{2}$, Jeanine M. Rhemtulla ${ }^{6}$, Jeffrey A. \\ $\underline{\text { Cardille }}^{1,4}, \underline{\text { Kees Vanderheyden }}^{7}, \underline{\text { Geneviève Poirier-Ghvs }}^{7}, \underline{\text { Delphine Renard }}^{1,8}, \underline{\text { Sylvestre Delmotte }}^{1}, \underline{\text { Cécile H. Albert }}^{2,9}, \underline{\text { Bronwyn }}$ \\ $\underline{\text { Rayfield }}^{2}$, Maria Dumitru $^{2}, \underline{\text { Hsin-Hui Huang }}^{10}{ }^{10}$ Martine Larouche $^{8}, \underline{\text { Kate N }}$. Liss ${ }^{1}$, Dorothy Y. Maguire ${ }^{1}, \underline{\text { Kyle T. Martins }}^{2}, \underline{\text { Marta }}$ \\ Terrado $^{1,11}$, Carly Ziter $^{1,2}, \underline{\text { Lucie Taliana }}^{1}$ and $\underline{\text { Karine Dancose }}^{1}$
}

\begin{abstract}
To maximize specific ecosystem services (ES) such as food production, people alter landscape structure, i.e., the types of ecosystems present, their relative proportions, and their spatial arrangement across landscapes. This can have significant, and sometimes unexpected, effects on biodiversity and ES. Communities need information about how land-use activities and changes to landscape structure are likely to affect biodiversity and ES, but current scientific understanding of these effects is incomplete. The Montérégie Connection (MC) project has used the rapidly suburbanizing agricultural Montérégien landscape just east of Montreal, Québec, Canada, to investigate how current and historic landscape structure influences ES provision. Our results highlight the importance of forest connectivity and functional diversity on ES provision, and show that ES provision can vary significantly even within single landuse types in response to changes in landscape structure. Our historical analysis reveals that levels of ES provision, as well as relationships among individual ES, can change dramatically through time. We are using these results to build quantitative ES-landscape structure models to assess four future landscape scenarios for the region: Periurban Development, Demand for Energy, Whole-System Crisis, and Green Development. These scenarios integrate empirical and historical data on ES provision with local stakeholder input about global and local social and ecological drivers to explore how land-use decisions could affect ES provision and human well-being across the region to the year 2045. By integrating empirical data, quantitative models, and scenarios we have achieved the central goals of the MC project: (1) increasing understanding of the effects of landscape structure on biodiversity and ES provision, (2) effectively linking this knowledge to decision making to better manage for biodiversity and ES, and (3) creating a vision for a more sustainable socialecological system in the region.
\end{abstract}

Key Words: biodiversity; ecosystem services; landscape connectivity; landscape structure; Montérégie; Québec; periurban; scenarios

\section{INTRODUCTION}

People everywhere rely on ecosystem services (ES) for their livelihood and well-being (MA 2005). ES provision depends on the biodiversity and ecological functions that characterize ecosystems (Gonzalez et al. 2011), which in turn are influenced by landscape structure, i.e., the types of ecosystems present, their relative proportions, and their spatial arrangement across landscapes (Gordon et al. 2008, Mitchell et al. 2015). Although people around the world continue to alter landscapes in farreaching ways to maximize specific ES such as food production (Foley et al. 2005, Ramankutty et al. 2008), our understanding of the links between landscape structure, biodiversity, ecosystem functioning, and ES lags behind (Kremen and Ostfeld 2005, Carpenter et al. 2009, Biggs et al. 2012). This means that people are changing landscapes to alter service provision, but are doing so with incomplete information about how these changes will affect multiple services and human well-being.

Landscape alterations typically involve fragmenting, isolating, or even replacing natural ecosystems (Foley et al. 2005, MA 2005), resulting in smaller and more isolated habitat patches, changes to patch shape and condition, and reduced landscape connectivity (Hanski 2005, Haddad et al. 2015). Loss of connectivity and fragmentation of natural habitat can affect the movement of organisms and material (Mitchell et al. 2013), as well as levels of biodiversity (Fahrig 2003, Hanski 2005) and ecosystem function (Gonzalez et al. 2009). Because movement of organisms and material as well as maintenance of biodiversity are key for many ES (Kremen et al. 2007, Gordon et al. 2008, Cardinale et al. 2012, Balvanera et al. 2014), changes to landscape connectivity can substantially alter the provision of multiple ES at different scales (Kremen and Ostfeld 2005, Carpenter et al. 2009, Biggs et al. 2012, Mitchell et al. 2013, 2015). For example, pollination and pest regulation depend on the movement of arthropods from noncrop habitat fragments to fields (Ricketts et al. 2008, ChaplinKramer et al. 2011) and can be influenced by the diversity of pollinator and predator communities (Hoehn et al. 2008, Letourneau et al. 2009). However, except for a few select ES, we have limited examples of how changes to landscape structure and connectivity affect ES provision, especially at scales relevant to ecosystem management and planning in real-world socialecological systems (Biggs et al. 2012).

Managing landscapes for ES provision requires an understanding of how policy, governance, and human institutions interact to bring about changes in landscape structure and ES (Andersson et al. 2007, Diaz et al. 2011). However, because of the lack of scientific information about how land-use decisions affect

\footnotetext{
${ }^{1}$ Department of Natural Resource Sciences, McGill University, ${ }^{2}$ Department of Biology, McGill University, ${ }^{3}$ School of Geography, Planning and Environmental Management, University of Queensland, ${ }^{4}$ McGill School of Environment, McGill University, ${ }^{5}$ Québec Centre for Biodiversity Science, ${ }^{6}$ Department of Forest and Conservation Sciences, University of British Columbia, ${ }^{7}$ Centre de la Nature Mont Saint-Hilaire, ${ }^{8}$ Department of Geography, McGill University, ${ }^{9}$ Aix Marseille Université, CNRS, IRD, Avignon Université, Institut Méditerranéen de Biodiversité et d'Écologie (IMBE), ${ }^{10}$ Department of Bioresource Engineering, McGill University, ${ }^{11}$ Catalan Institute for Water Research (ICRA)
} 
multiple ES at different scales, uncertainty about how to incorporate this information into decisions, and poor communication between researchers and decision makers (Likens 2010, Dietz 2013), frequent calls for ES to be "explicitly and systematically integrated into decision-making" (National Research Council 2004, Daily et al. 2009:22) remain unanswered. Most existing ES models were developed to address a single ES at a single spatial scale (Carpenter et al. 2009) and ignore interactions among services, even if those interactions might affect the ES of primary interest. Additionally, most studies only offer a snapshot in time, which is unlikely to be sufficient to understand rates of change in ES provision or their interactions (Renard et al. 2015). Finally, most ES models use the amount of each land-use or land-cover type as a proxy for ES, largely ignoring how changes to landscape structure might alter relationships between land use/land cover and ES. There is increasing evidence that these simple proxies do a poor job of representing actual patterns of ES provision (Eigenbrod et al. 2010, 2011) and that relationships between land use/land cover and ES vary significantly depending on the scale considered (Anderson et al. 2009, Holland et al. 2011).

At the same time, landscapes around the world are increasingly being managed for landscape structure, and in particular connectivity, to conserve threatened biodiversity of high conservation concern (e.g., the Yellowstone to Yukon Conservation Initiative, http://y2y.net). However, these approaches rarely explicitly incorporate ES. Decision making for multiple ES and biodiversity conservation at landscape scales will be improved with more robust theory, data, and models that link landscape structure, biodiversity, ecosystem functions, and ES at the scales where decisions are made and where management efforts will be most effective (Carpenter et al. 2009).

To address these knowledge gaps, we developed a detailed case study in the Montérégie, an agricultural region in southern Québec, Canada. The Montérégie Connection (MC) project has three main goals: (1) to develop and empirically evaluate a robust conceptual framework detailing the links between landscape structure, biodiversity, and ES (Fig. 1); (2) to build landscape models that can be used to quantitatively explore future provision of ES under various scenarios, enabling exploration of how local decision making affects the provision of ES; and (3) to expand and deepen channels of communication with local and regional nongovernmental organizations (NGOs) and governance bodies to ensure long-term input on research and effective use of research products and outcomes. We have used empirical field studies of landscape structure, biodiversity, and the provision of multiple ES across the Montérégie to build preliminary quantitative landscape models that link land use/land cover with the provision of multiple ES. These models are being paired with scenarios of future land use/land cover developed in collaboration with local stakeholders, and will be informed by our historical analyses of ES in the Montérégie to predict future provision of multiple ES. These models continue to be updated and improved using project results. Here, we describe our process for understanding landscape structure-biodiversity-ES relationships in the Montérégie, how we developed ES models and future scenarios, and how these components are being linked to inform land management in the region.
We chose the Montérégie region in southern Québec because it is representative of human-dominated agricultural landscapes that are currently seeing substantial pressure from periurban development. This increased intensity of human use requires effective management of landscape structure into the future for both ES and biodiversity. Historical clearing of native ecosystems for agriculture in the Montérégie has driven changes in landscape structure that have had far-reaching consequences for the current provision of multiple ES. In particular, these changes have increased food production, but degraded regulating ES such as water quality regulation and carbon sequestration (RaudseppHearne et al. 2010). Currently, substantial periurban expansion and population growth in the region are increasing demand for a diverse suite of ES. These pressures are forecast to increase into the future (ISQ 2014). At the same time, there is a desire to establish a greenbelt and create green corridors across the region to conserve, and potentially even increase, regional biodiversity (MRC-VR 2007). Understanding how human actions that alter landscape structure, and connectivity in particular, are expected to affect biodiversity, multiple ES, and ultimately human wellbeing (Fig. 1) is critical for effective management of this region. This motivation is central to our research and informs the main conceptual framework and questions that underlie the $\mathrm{MC}$ project.

Fig. 1. Conceptual linkages between landscape structure and human well-being in the social-ecological system of the Montérégie Connection Project. Landscape structure, i.e., the types of land use and land cover present, as well as their configuration and connectivity, affects both levels of biodiversity and the different ecosystem functions present in landscapes. This in turn affects all types of ecosystem services (e.g., provisioning, regulating, and cultural), human well-being, and eventually social values, institutions, and decisions. These social changes will affect people's actions in the landscape, in turn changing how they use the land and affect landscape structure.

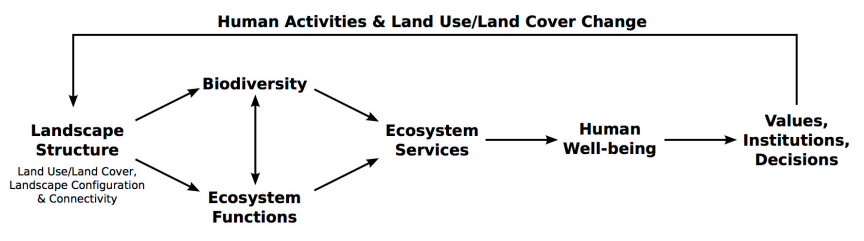

\section{THE MONTÉRÉGIE AND THE RICHELIEU \\ WATERSHED}

The MC project study area is located to the east and south of Montreal, the eighth largest city in North America (Fig. 2), and is focused on the Mixedwood Plains ecozone and St Lawrence Lowlands ecoregion of southern Québec, Canada. This region has warm summers and cold, snowy winters with a mean annual temperature of $\sim 5^{\circ} \mathrm{C}$ and average seasonal temperatures that range from $16.5^{\circ} \mathrm{C}$ in the summer to $-7^{\circ} \mathrm{C}$ in the winter. Mean annual precipitation varies between 800 and $1000 \mathrm{~mm}$. The terrain is mostly flat and below $150 \mathrm{~m}$ is dominated by poorly drained clay deposits upon which gleysolic soils have developed (Jobin et 
Fig. 2. Land use/land cover in the Montérégie and surrounding area. (A) The location of Québec within Canada, (B) the location of the Montérégie in southeastern Québec, and (C) southeastern Québec including Montreal and the Montérégie. The Montérégie Connection project's fieldwork, models, and scenarios have focused on the Vallée-de-Richelieu Municipalité Regionale Comté (VR-MRC; outlined in black). The VR-MRC includes Mont Saint-Hilaire (outlined in blue), which encompasses both the Centre de la Nature du Mont Saint-Hilaire and the Gault Nature Reserve. Proportions of land use within the VR-MRC are also shown.

(A)

(B)

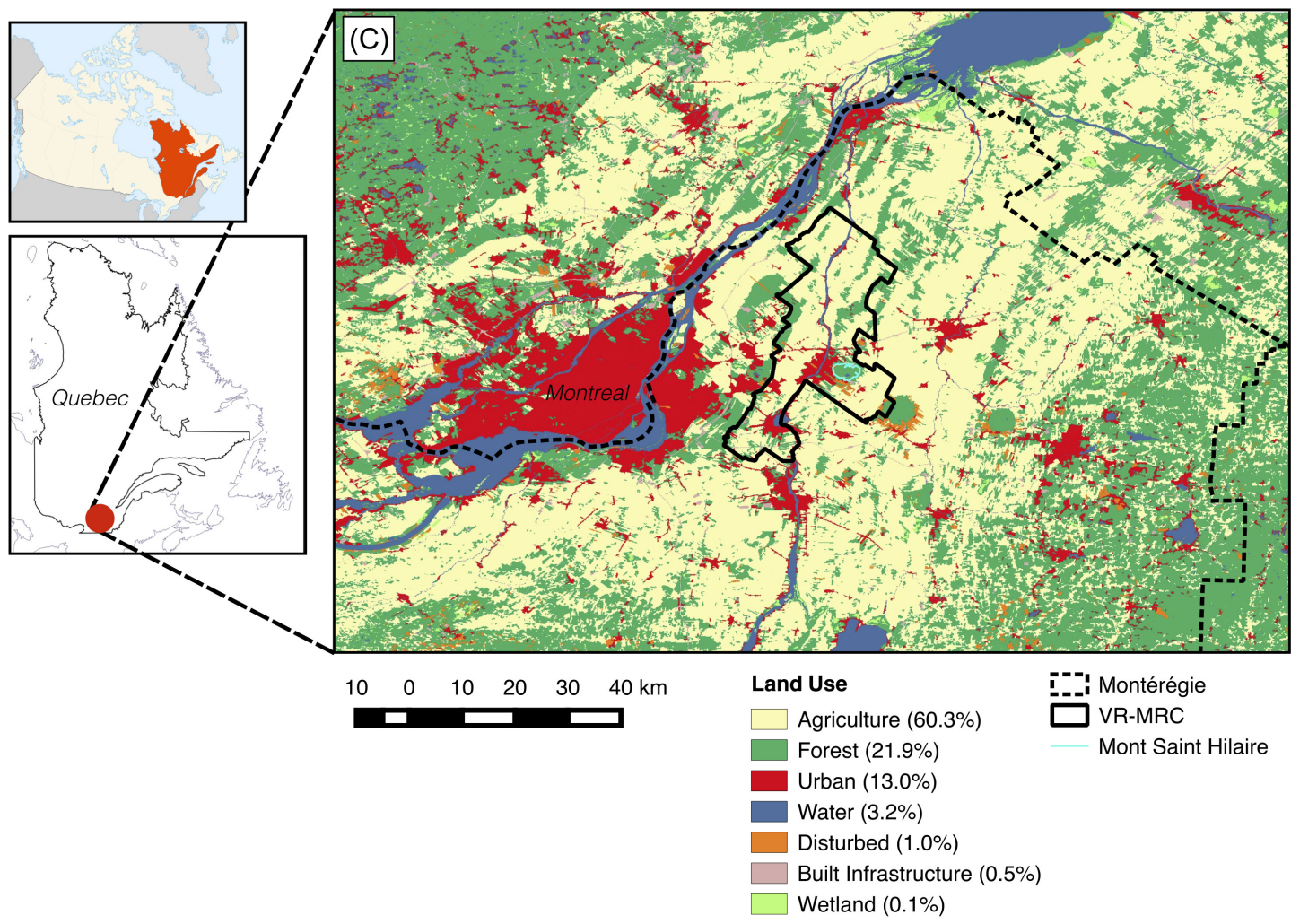

al. 2010). However, several Montérégien hills, isolated plutonic intrusions that range from 200 to $400 \mathrm{~m}$ in height, are also present (Feininger and Goodacre 1995). These hills are forested, often reserved for recreation, and are important reservoirs of biodiversity in the region.

The Montérégie in its entirety covers $\sim 11,000 \mathrm{~km}^{2}$ and has a population of approximately 1.4 million people ( $18 \%$ of Québec s population). It contains ecosystems with the highest levels of biodiversity in the province (Tardif et al. 2005) and consists of a mosaic of urban, periurban, rural, and extensive agricultural areas. Rural communities and agriculture have historically dominated the Montérégien landscape. A shift in agricultural production from dairy farming to intensively managed corn and soybean fields has occurred in recent decades, leading to more annual crops, fewer farms, and increases in pesticide and fertilizer use (Bélanger and Grenier 2002, Jobin et al. 2010). Apple orchards are concentrated on the well-drained gravel slopes of the Montérégien hills. Numerous, mostly small, residual deciduous and mixedwood forest fragments are present and provide important ES, including maple syrup production, but very few municipalities have more than $30 \%$ forest cover, based on land cover analysis using 2009 Landsat 5 images (M. Dumitru, unpublished data). The region is currently undergoing significant residential development and expansion of periurban areas because of its proximity to Montreal (Dupras and Alam 2014). This is causing significant loss of biodiversity (Bélanger and Grenier 2002, Jobin et al. 2010) and is putting pressure on local land managers to achieve provision of multiple ES across the landscape.

Fieldwork, modeling, and scenario development for the MC project have focused on the Vallée-de-Richelieu Muncipalité Region Comté(VR-MRC) or Regional County Municipality (Fig. 2). MRCs are Québec-specific political entities that provide regional governance across a number of smaller, local municipalities. Their responsibilities include planning and managing land use, making and administering urban planning rules, and managing watercourses and agricultural drainage across their jurisdictions, among other duties. The VR-MRC covers $\sim 75$ $\mathrm{km}^{2}$, has a population of $\sim 120,000$, and consists of 13 municipalities located on either side of a $\sim 63-\mathrm{km}$ stretch of the Richelieu River. The first Biosphere Reserve designated in Canada under the United Nations Educational, Scientific and Cultural Organization Man and the Biosphere Program is centered on Mont Saint-Hilaire, a Montérégian hill within the VR-MRC. It incorporates a tightly coupled social-ecological system including a vibrant human community, a research center in McGill University's Gault Nature Reserve (http://www.mcgill.ca/gault/), and a variety of natural ecosystems. Importantly, the Gault Nature 
Reserve is partnered with the Centre de la Nature Mont SaintHilaire (http://www.centrenature.qc.ca), a nonprofit organization created in 1972, separate from McGill University, that serves as an outreach vehicle to aid in regional conservation efforts. Much of the current periurban development in the VR-MRC is focused around Mont Saint-Hilaire on either side of the Richelieu River.

Numerous ES are provided across the Montérégie, including food, drinking water, connections to nature, opportunities for recreation, nature-based tourism, carbon sequestration and storage, nutrient retention, pollination, pest regulation, and soil quality regulation (Raudsepp-Hearne et al. 2010, Ziter et al. 2013, Mitchell et al. 2014a, 2014b, Martins et al. 2015). Past work has shown that these ES are provided heterogeneously across the landscape, with many positive and negative interactions between ES at different spatial scales. This has resulted in the presence of ES bundles, distinctive sets of ES that occur together repeatedly across the landscape (Raudsepp-Hearne et al. 2010).

\section{RESEARCH FRAMEWORK AND SCENARIO DEVELOPMENT}

The MC project aims to understand how landscape structure affects biodiversity, ecosystem function, and the provision of different ES (Table 1, Fig. 1), and to link this ecological knowledge to the values, institutions, and decisions that determine human actions, especially those that determine landscape structure. Using a combination of geographic information system, fieldwork, and historical analyses, we have collected empirical data about the relationships between landscape structure, biodiversity, and the provision of multiple ES at multiple spatial scales in our study area (Fig. 3). At the finest scale, approximately the size of a single farm, field, orchard, or forest fragment, we concentrated on how biodiversity and ES vary spatially within land-use types, i.e., with distance from forest in fields or distance to edge in forest fragments. At the scale of a few square kilometers, we focused on understanding how landscape structure, in particular connectivity between forest fragments, affects biodiversity and ES provision. Although each project component differed in its consideration of specific landscape structure variables, land uses, spatial/temporal scales, species groups, and ES, overall results point to the general importance of landscape structure for biodiversity and services, with a significant role for human management in mediating these relationships.

Parallel to this empirical work, we conducted a historical analysis of ES provision across the Montérégie. Combining data from censuses, provincial ministries, and archives of regional associations, we quantified food provision indicators (five field crops, three livestock types, and dairy and maple syrup production) from 1911 to 2006 and nine other provisioning, regulating, and cultural ES from 1971 to 2006 (Table 1). Our main goals here were to identify bundles of ES (i.e., sets of positively correlated ES) and describe if, and how, their provision and spatial distribution changed through time.

Using our empirical data, historical analyses, other existing landscape structure data, literature on ES in the region, and expert knowledge, we built preliminary spatially explicit models that relate landscape structure to different ES. These models are currently being updated to more fully take into account our empirical and historical analyses. Because the data available at the VR-MRC scale are less detailed than our empirical data, it has not been possible to include all of the ES measured in the field in
Table 1. Ecosystem services and biodiversity measured and modeled in the Montérégie Connection project.

\begin{tabular}{lccc}
\hline \hline $\begin{array}{l}\text { Ecosystem Service } \\
\text { or Species Group }\end{array}$ & $\begin{array}{c}\text { Empirical } \\
\text { Fieldwork }\end{array}$ & $\begin{array}{c}\text { Historical } \\
\text { Analysis }\end{array}$ & $\begin{array}{c}\text { Incorporated } \\
\text { in Models/ } \\
\text { Scenarios }\end{array}$ \\
\hline $\begin{array}{l}\text { Provisioning } \\
\text { Crop production }\end{array}$ & Yes & Yes & Yes \\
$\begin{array}{l}\text { Pork \& cattle } \\
\text { Maple syrup }\end{array}$ & - & Yes & - \\
Regulating & - & Yes & Yes \\
Carbon storage & Yes & Yes & Yes \\
Pollination & Yes & - & Yes \\
Pest regulation & Yes & - & Yes \\
Flood regulation & Yes & Yes & - \\
Decomposition & Yes & - & - \\
Soil fertility & Yes & - & - \\
Water quality & Yes & - & Yes \\
Cultural & & & \\
Nature appreciation & - & - & Yes \\
Deer hunting & - & Yes & - \\
Outdoor activities/ & - & Yes & Yes \\
Tourism & & & \\
& & & - \\
Biodiversity & & - & Yes \\
Forest plant diversity & Yes & - & Yes \\
Arthropod diversity & Yes & - & - \\
Bird diversity & - & - & \\
Mammal diversity & - & - & \\
Aquatic diversity & Yes & & \\
\hline
\end{tabular}

Fig. 3. Methodological framework of the Montérégie Connection project, linking different data layers of landscape structure, biodiversity, and ecosystem services (ES) across temporal and spatial scales. Contemporary research and field data on ES provision, land use/land cover, biodiversity, forest connectivity, and distance-decay effects have been combined with historical analyses of ES and land use/land cover to create quantitative ES models. These models are now being used to predict future ES provision by linking them with stakeholderinformed land-use/land-cover change scenarios. Stakeholder input also helped inform our contemporary research questions and methods and the creation of ES models (dashed lines).

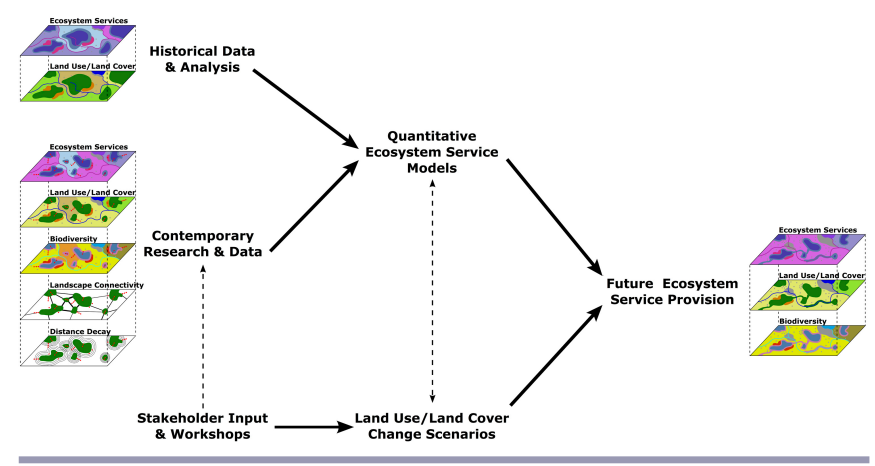


these models (Table 1). This is particularly true for those ES that have no information available about their relationships with landscape structure or their historical trends. Instead, the models have been constructed and will be further developed around a bigpicture approach with simplified relationships based on those quantified in our field and historical studies. Importantly, the models do not simply predict ES provision based on land use/land cover alone, but also explicitly take into account the effects of landscape structure on ES provision that we have come to understand from our empirical work. Thus, the models will be an important advance from a benefits-transfer approach of mapping ES based solely on land use/land cover toward a more realistic representation of how ES provision can change with the structure of the landscape.

In conjunction with model development, we developed scenarios of possible futures for the VR-MRC in collaboration with local stakeholders, helping directly link their values, needs, and knowledge with our research (Cowling et al. 2008, Lamarque et al. 2013). Scenarios are sets of plausible stories about what the future might look like and have been shown to be a useful alternative to single-future strategic planning processes (Wollenberg et al. 2000, Bennett et al. 2003). They can also be used to guide decision making that is robust under a wide range of possible futures (Peterson et al. 2003a, Van der Heijden 2005) and have been used effectively in collaboration with local stakeholders to address issues of concern (Peterson et al. 2003b). By creating scenarios that explicitly include changes in landscape structure and that can incorporate our quantitative landscape models, we have been able to use the scientific knowledge produced by the MC project to inform discussions of landscape management and decision making in the Montérégie.

We identified key drivers of future land use changes in the VR$\mathrm{MRC}$ and generated scenarios through two workshops organized with the main stakeholders in the region, including representatives of NGOs, municipalities, ministries of environment and agriculture, farmers, and the local chamber of commerce. These drivers came from a retrospective analysis of past land-use changes, an understanding of global drivers affecting land-use change in Canada, and aspects specific to the VR-MRC context, such as urban sprawl associated with a growing Montreal population. We then classified these drivers according to their potential influence and level of uncertainty, and selected two main drivers, i.e., energy sources and the nature of population growth, as the basis for scenario development. In subgroups, workshop participants developed nine storylines that were then synthesized into four scenarios by the research team. Finally, these scenarios were modified and validated by a select group of stakeholders acting as an advisory board for the project.

As the scenario process plays out, we will fully assess how ES provision and biodiversity will change across the VR-MRC in each of the four scenarios using our final ES-landscape structure models and will then discuss with stakeholders how changes in drivers will affect landscape structure to produce differences in the provision of multiple ES (Fig. 3). At present, we have only used our preliminary ES-landscape models to assess how future ES provision and biodiversity might vary in each scenario. To do this, we first adapted a land-use change model to map anticipated future land use under each scenario. Each map was then discussed, modified, and validated with our stakeholder advisory board, taking into account unique aspects of the region to ensure realistic land uses and landscape structure. Importantly, each scenario differs from the others in terms of landscape composition, landscape structure, and connectivity. These land-use maps have served as input for our preliminary ES-landscape models. Next, the results from our empirical work were used to develop simple relationships between landscape structure and ES provision for our preliminary models. Initial results from this analysis have been discussed with stakeholders to develop adaptive strategies for the sustainable management of multiple ES in the region. Bringing the scenarios and the modeled ES outcomes from the scenarios back to our stakeholders has led to interesting discussions that highlight the important learning that is happening among our stakeholder group as they participate in the project. This discussion has also helped us determine the important values of different stakeholder groups and how these values influence land management decisions in the region. These results will be further refined as our models are finalized, and the full results of our paired scenario-ES model analyses for all 11 ES across the landscape (Table 1) will be communicated to regional stakeholders. The MC project illustrates the usefulness of the scenario approach, which involves researchers working closely with local communities to build, use, and refine tools to grapple with the challenges of environmental management in the face of local, regional, and global change.

\section{EMPIRICAL RESULTS}

Our empirical results demonstrate that landscape structure has important and varied effects on ES provision. In particular, increased forest fragment connectivity reduced arthropod pest control within maple tree stands (Fig. 4B, Maguire et al. 2015) as well as insect herbivory and aphid numbers in nearby soybean fields (Fig. 4A, Mitchell et al. 2014b), but had little effect on aboveground carbon storage (Ziter et al. 2013). The relative locations of riparian buffers and nutrient sources to agricultural fields and watercourses also play a critical role in water quality regulation in the region (Terrado et al. 2014). We found that ES provision varies according to distance-dependent relationships within single land-use categories. For example, soybean yield increases asymptotically with distance from forest (Fig. 4C), whereas seed set in apple orchards declines linearly as distance to meadow increases (Fig. 4D, Martins et al. 2015). Importantly, the nature of the relationships between landscape structure and ES provision varies widely across different ES. This is significant because it means that the consequences of a single change in landscape structure will vary substantially for different ES, significantly increasing the difficulty for managers who wish to manage for multiple services.

Additionally, although landscape structure has readily apparent effects on the diversity of different species groups, the consequences of these for ES provision are not consistent. For example, distance from forest and field width alter soybean pest and arthropod predator diversity but not pest regulation (Mitchell et al. 2014a), and edge effects alter tree diversity in forest fragments but not carbon stocks (Ziter et al. 2014). Contrastingly, greater functional diversity of bees increases apple fruit and seed set in orchards (Fig. 4E, Martins et al. 2015), whereas greater tree functional diversity increases aboveground carbon storage in unmanaged forest fragments (Fig. 4F, Ziter et al. 2013). 
Fig. 4. Highlighted results from the Montérégie Connection project. Relationships between (A) forest fragment isolation (PI indicates proximity index) and herbivory regulation in adjacent soybean fields; (B) forest fragment connectivity and herbivory regulation in different types of maple tree stands; (C) distance from forest fragment and crop yield; (D) distance from meadow and pollination services; (E) woody plant functional diversity (functional dispersion) and carbon storage; and $(\mathrm{F})$ native pollinator functional diversity (functional dispersion) and pollination services. In each, shaded areas or error bars indicate $95 \%$ confidence intervals. In panels A, C, and E, we show individual data points; in panels $\mathrm{D}$ and $\mathrm{F}$, the small lines along the $\mathrm{x}$-axis indicate sampled distances from meadow and pollinator functional diversity, respectively. Reproduced from Mitchell et al. 2014b (panels A and C); Martins et al. 2015 (panels D and F); and Ziter et al. 2013 (panel E).

(A)
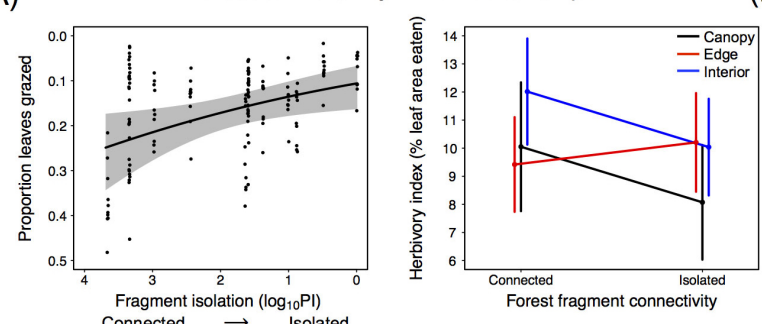

(C)
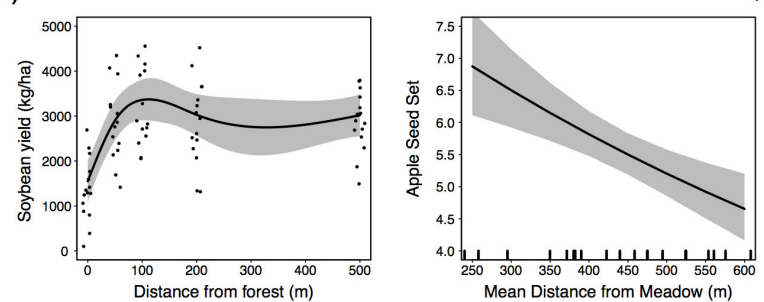

(E)

Biodiversity-ES relationships
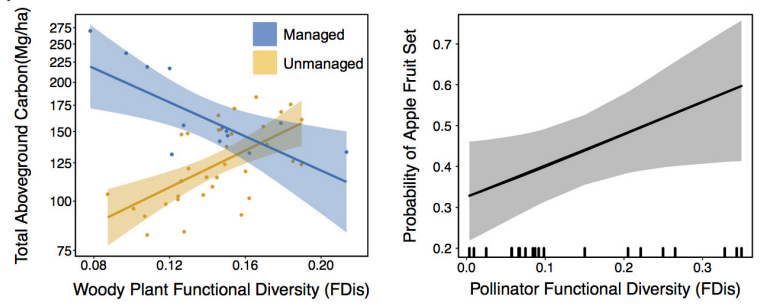

Results from our historical analysis show that not only individual ES change through time and space, but entire bundles of services change in response to changes in land use and management (Renard et al. 2015). Regional municipalities in the 1970s tended to be ES generalists, providing a broad mix of services, but by 2006 most had specialized in the production of only a small set of services. These results provide evidence of the dynamic nature of ES interactions and show how a historical approach can contribute to identifying the drivers behind these changing relationships.

\section{SCENARIO DESCRIPTIONS}

The four scenarios (Box 1) extend to 2045 and differ in regard to two main drivers: (1) the sources of energy used for housing, transportation, and agriculture, as well as the level of selfproduction of energy in the region; and (2) the extent to which urban sprawl is contained or expanded. Complete storylines can be found online (http://MonteregieConnection.com).

\section{Box 1: Four Scenarios}

\section{Periurban Development}

This scenario explores what happens when urban sprawl simultaneously increases energy demand and significantly alters the structure of the landscape and its ability to provide ES (Fig. 5). Because of massive immigration to the region (a $0.9 \%$ increase in population per year) and a failure of urban densification programs, urban area expands by approximately $80 \%$ in the Montérégie. New suburban developments built on farmland and forest patches along the Richelieu River are facilitated by upgraded highway connections into the city center of Montreal. Increased urban development around the south of Mont SaintHilaire leads to widespread loss of forest and farmland. Remaining farms are large and are planted nearly entirely with soy and corn. Loss of small forest patches between small agricultural fields dramatically reduces landscape connectivity, causing declines in biodiversity and ES. Ultimately, quality of life is reduced as access to green space and agrotourism declines.

\section{Demand for Energy}

A global energy shortage leads to the end of Québec's shale gas hydraulic fracturing (fracking) moratorium (Fig. 6). Subsequent shale gas development in the north of the VR-MRC negatively impacts water supply, water quality, and agricultural production. At the same time, wind power installations are developed along main highways. Urban expansion is limited, with an emphasis on increased urban density. Suburban development results in some loss of farmland, but this is balanced by forest clearing and agricultural expansion in the north. Shale gas development improves the economic welfare of the region, allowing land managers to strengthen forest protection, improving access to outdoor recreation and increasing climate mitigation through carbon storage.

\section{Whole-System Crisis}

Urban expansion is almost nonexistent through 2020 as a deep economic crisis reduces population growth in the region, driving down housing prices (Fig. 7). In addition, exotic insect pests, in particular the Emerald Ash Borer (Agrilus planipennis) and Asian Long-Horned Beetle (Anoplophora glabripennis), attack hardwood trees and cause widespread degradation and loss of forests and maple trees, resulting in reduced maple syrup production. This leads to agriculture expansion instead of intensification and a return to a pasture-based livestock agricultural system, as well as a shift toward market gardens on high-value agricultural land. Marginal farmland is reforested for wood production (agroforestry) or climate mitigation (carbon storage).

\section{Green Development}

A significant shift toward sustainable development occurs in the Montérégie (Fig. 8). The regional population continues to increase 
at an average rate of $0.7 \%$ per year, but urban expansion is limited because of effective efforts toward densification of existing and new urban centers. These new urban areas incorporate green corridors that include bicycle paths and rail connections to the Montreal city center. Renewable energies are prioritized. In an effort to create a green corridor network in the region, every hectare of forest lost to new urban development is compensated for by planting two new hectares of forest. Protected areas cover $17 \%$ of the region by 2035 . Most agricultural lands have adopted agroforestry principles, which leads to a significant increase in forested lands, as well as maple products, recreation, and mushroom crops.

Fig. 5. The Vallée-de-Richelieu Muncipalité Region Comté in the Periurban Development scenario. In this scenario increased residential growth drives loss of farmland and forests, resulting in loss of landscape connectivity and agricultural production in certain areas. Scenario illustration is used with permission of the artist, Denis Bainville.

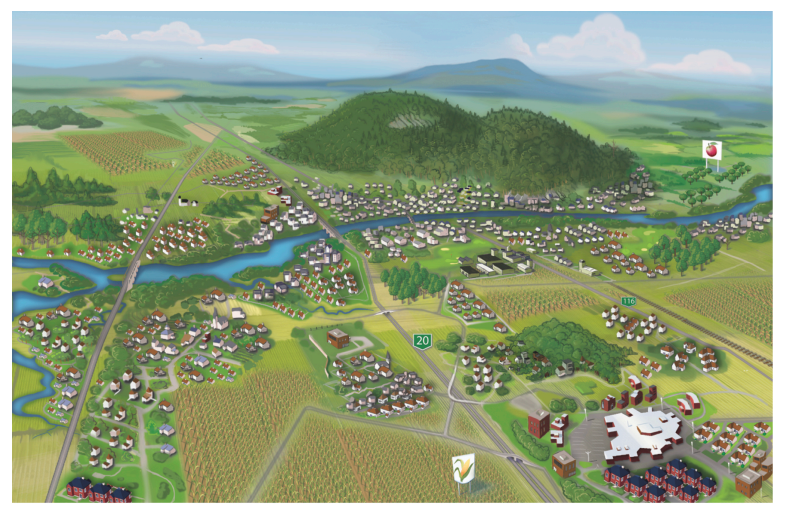

Fig. 6. The Vallée-de-Richelieu Muncipalité Region Comté in the Demand For Energy scenario. In this scenario shale gas development expands, resulting in farmland loss, while urban and residential development is limited. Wind power installations are also developed. Scenario illustration is used with permission of the artist, Denis Bainville.

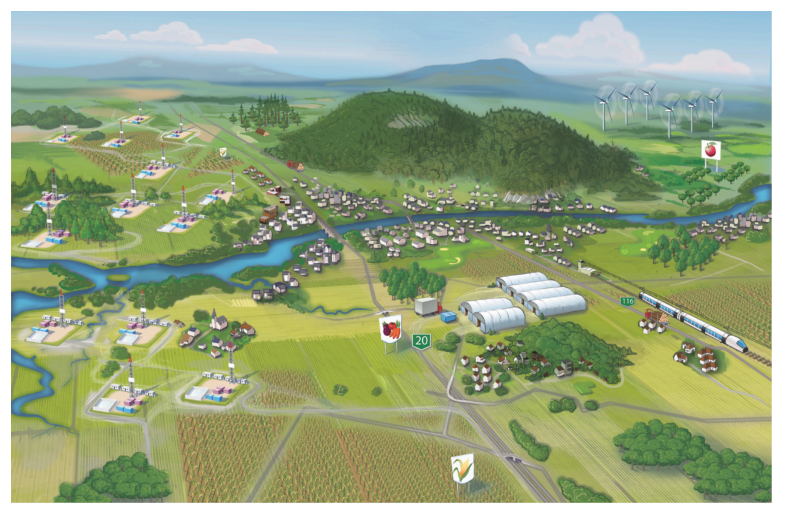

Fig. 7. The Vallée-de-Richelieu Muncipalité Region Comté in the Whole-System Crisis scenario. In this scenario an economic crisis drives residential densification while the Asian Long-Horned Beetle (Anoplophora glabripennis) invades, decimating the maple tree populations. Agricultural production shifts to pasture-based livestock, while marginal farmlands are converted to agroforestry. Scenario illustration is used with permission of the artist, Denis Bainville.

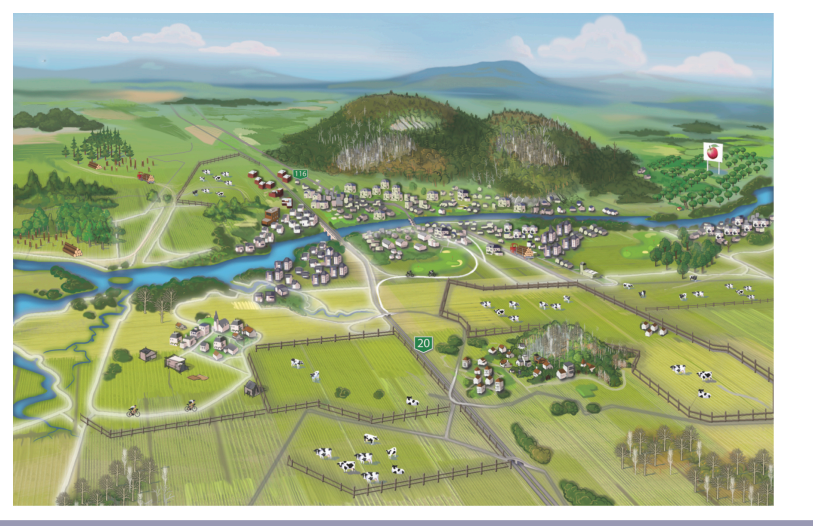

Fig. 8. The Vallée-de-Richelieu Muncipalité Region Comté in the Green Development scenario. Here there is a shift toward sustainable development, where renewable energy, green tramways, green corridors, protected areas, and agriculture that incorporates agroforestry principles are emphasized. Scenario illustration is used with permission of the artist, Denis Bainville.

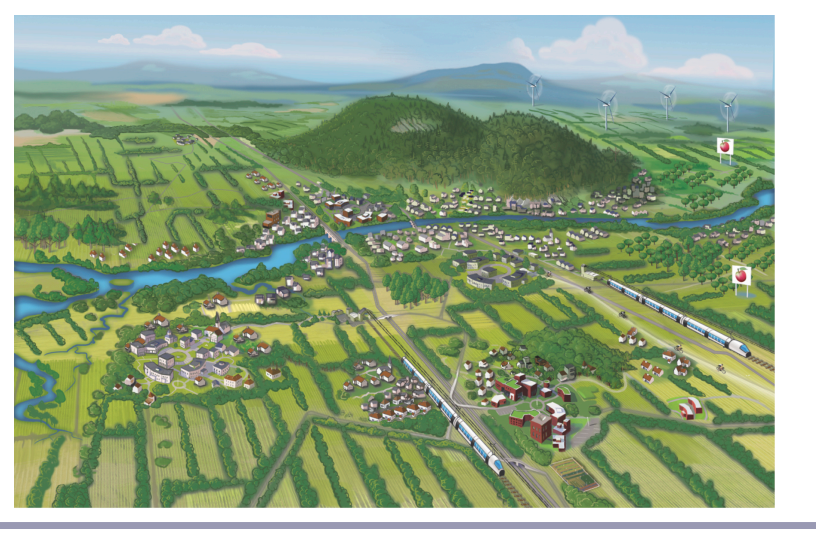

\section{DISCUSSION}

The main aim of the MC project is to improve understanding of the links among landscape structure, biodiversity, and ES provision, and to use this knowledge to inform land-use decisions. To do this effectively, we have combined a wide range of approaches, from conventional ecological fieldwork detailing ES and land-use relationships to historical analysis of ES through time. Most importantly, the incorporation of scenarios coupled with preliminary quantitative landscape ES models has allowed the MC project to investigate the feedbacks between landscape 
structure, ES provision, and human activities. These results will continue to be refined as we develop our ES-landscape structure models. Our use of scenarios also allowed the MC project to capitalize on trusting and long-term relationships with regional stakeholders. This has been key to effectively incorporating scientific knowledge of ES provision across the Montérégie into local and regional decision making.

Empirical results from the MC project suggest that landscape management decisions need to take into account landscape structure to effectively manage ES. We observed strong effects of landscape structure on multiple ES, with the form of these relationships varying widely between different ES. Currently, explicit consideration of landscape structure in ES studies is not common. In part, this is because of the fact that ES modeling efforts so far have focused on simplified landscape models; understanding the more complicated effects of landscape structure on ES has not been a priority, given other knowledge gaps. However, landscape planning usually involves decisions about how different land uses/land covers should be spatially arranged (e.g., Phalan et al. 2011). Without information about how spatial arrangement of land uses/land cover will affect the provision of ES, it is difficult to accurately manage for ES through landscape planning. Thus, there is a critical need to consider and quantify the links between landscape structure and ES provision (Chaplin-Kramer et al. 2015, Mitchell et al. 2015). Development and application of the MC project's conceptual framework, and quantification of the empirical relationships between ES and landscape structure in the MC project have demonstrated the importance of landscape structure for ES provision in suburbanizing agricultural landscapes.

Empirical results from the MC project also emphasize the fact that human activities, by changing landscape structure and connectivity, have important effects on ES provision and biodiversity. In particular for the Montérégie, our results demonstrate how agricultural expansion and forest fragmentation are important drivers. Landscape connectivity, fragmentation, and distance-dependent changes in ES provision all play a role in determining overall ES provision across the Montérégie landscape. These effects are usually unique for each ES, varying across and within land-use types and often mediated by changes in biodiversity. These insights highlight the weakness of many current benefit-transfer approaches to ES modeling, in which each land use/land cover is assigned a static ES value and effects of landscape structure on ecological dynamics or levels of biodiversity are not considered. Instead, our results emphasize that ES provision can vary at much finer scales across landscapes and that understanding these patterns and the underlying ecological mechanisms is key to managing landscapes for ES provision. An important consequence of these results is that heterogeneity in landscape structure at different scales may be needed to maximize multiple ES across agricultural landscapes like the Montérégie (Mitchell et al. 2014b). However, the specific spatial scales and levels of heterogeneity needed to maximize different ES are uncertain, and in some cases optimizing landscape heterogeneity for one ES might lead to a detrimental effect on a different ES or biodiversity conservation (Fahrig et al. 2011, Seiferling et al. 2014). This highlights the difficulties in designing and planning at the landscape scale for multiple ES and biodiversity.
An important challenge that emerged during the $\mathrm{MC}$ project was measuring ES and biodiversity across the VR-MRC at multiple spatial scales. Past work has demonstrated the scale-dependency of the ecological and social processes that underlie ES provision (Anderson et al. 2009, Isbell et al. 2011). Attempting to understand these relationships at multiple scales emerged as a key aspect of the project in two main ways. First, understanding how processes at different spatial scales interact to determine biodiversity and ES provision has allowed and will continue to allow us to model these different processes across the Montérégie in more complex and complete ways. In some cases, different empirical results emerged for ES measured at different scales, informing our understanding of the important processes for ES provision. For example, many of the strong trade-offs and synergies between ES at the regional scale (Raudsepp-Hearne et al. 2010) are weaker close to forest fragments, potentially because of forest fragments' ability to alter environmental conditions and affect the movement of organisms to nearby fields (Mitchell et al. $2014 b$ ). In other cases, the important scales for ES provision varied between ES; pest regulation depended on forest connectivity across kilometers (Fig. 4A, 4B), whereas crop provision was affected by distance from forest and meadow at the scale of hundreds of meters (Fig. 4C, 4D). Second, working at multiple scales allowed us to connect with stakeholders who manage the landscape at different scales (e.g., regional planners, city administrators, individual farmers). This has helped ensure that the results of our quantitative models and scenarios will be relevant to a wide range of stakeholders and will be incorporated into the variety of land management processes that take place across the region.

The MC project also highlights the importance of understanding changes in historical land-use/land-cover changes and ES provision. The long-lasting effects of past land use on current biodiversity patterns, ecosystem structure, and functioning are well recognized and have been widely applied in landscape and restoration ecology (Flinn and Vellend 2005, Hermy and Verheyen 2007, Vellend et al. 2007). The VR-MRC is no different, where current forest understory biodiversity is more related to historical landscape configuration than current conditions (Larouche 2013). However, most current ES research has only been able to quantify ES provision over a small period of time (but see MacDonald and Bennett 2009, Lautenbach et al. 2012, Renard et al. 2015). This means that the social-ecological dynamics operating at longer time scales that can influence ES provision have not been well described. For example, historical legacies of land use and land cover can significantly influence current ecosystem functioning and ES provision. Our historical analysis has allowed us to better understand how ES trade-offs and synergies vary through time and how important other variables, such as agricultural policy and management, are for ES provision. This will allow us to refine our quantitative ESlandscape models to better reflect these dynamics in the future and better understand how institutions and social networks can achieve effective long-term ES management (Swetnam et al. 1999).

Our use of scenarios coupled with preliminary landscape structure-ES models of intermediate complexity has and will continue to be critical to the MC project's goal of providing research products that will be used in regional decision making. 
The contemporary and historical landscape structure-ES relationships described in the MC project are complex, and the implications of these relationships for local stakeholders and decision makers into the future are often not immediately obvious. Explicitly linking land-use/land-cover and landscape structure changes in scenarios to biodiversity and ES provision has allowed us to translate these ecological relationships into results that are more easily understood by different stakeholders. An example is how the loss of forest connectivity from agricultural expansion leads to biodiversity and ES loss the Periurban Development scenario. This ability to translate complex social-ecological results to narratives has depended on building models with intermediate complexity that can link the data available at the scale of the VRMRC and information about landscape structure and ES dynamics with more straightforward future scenarios. We anticipate that the value of this approach will become even more evident as we continue to develop and improve our ES-landscape models and use them to explore how scenarios of land-use change will impact ES provision.

We have also found that scenario development itself can help effectively communicate scientific knowledge and results. Stakeholders were involved throughout the development and validation of the scenarios, which led to lengthy discussions among stakeholders about the future of the Montérégie, how land management decisions and changes to landscape structure might affect ES, and what specific ES different groups desired or valued. It also promoted conversations about the presence, importance, and effects of different drivers of land-use change in the region, e.g., energy use, urban development, economic changes, invasive species. These discussions themselves, separate from the preliminary ES provision results for each scenario, were a way to raise awareness and transfer knowledge of scientific research into regional decision making.

The divergent and varied futures imagined across the four scenarios have allowed us to begin to explore the combined consequences of global and local social drivers, human actions, and ecological pressures on ES provision. For example, the more sustainable future of Green Development contrasts with the global economic drivers evident in Demand for Energy or the ecological drivers of invasive species in Whole-System Crisis. These scenarios have resonated with local stakeholders, allowing them to better comprehend the effects on ES provision of changing landscape structure and how their decisions across the landscape can influence these processes. Stakeholders at project workshops have actively engaged with the scenarios, literally sitting on the edge of their seats while scenario results have been presented and immediately discussing these results with those around them, what they want the future of the region to be like, and how to achieve it. This level of stakeholder engagement is a powerful way to engage nonscientists in scientific research and dialogue around the management of social-ecological systems for ES.

We have also found that scenarios can effectively communicate constraints in ES management, i.e., that decisions to maximize certain ES, or decisions that impact specific ES, can lead to unexpected changes in other ES. For example, decisions to increase agricultural production by removing small forest patches in the Periurban Development scenario led to decreased opportunities for recreation and agrotourism in the region. Similarly, shale gas development in response to Demand for Energy degraded water supply and quality in the VR-MRC, but also indirectly allowed land managers to increase outdoor recreation and carbon storage through improved economic growth in the region. Our approach of coupling future scenarios with quantitative ES-landscape models has, so far, been key to the project's ability to translate conventional empirical ecological results and knowledge into tools and products that will be used by local and regional policy makers and land managers.

Developing effective scenarios in our study area meant connecting and communicating with a diverse set of stakeholders in both French and English. In this context, a career spent building trust and connections to one local group can have disproportionate benefits. We were able to capture the attention of our stakeholders and ensure their willingness to participate via one of our Principal Investigator's connections to the Centre de la Nature Mont SaintHilaire, with which he had built a trusting relationship over 15 years while director of McGill's Gault Nature Reserve. These types of bridging organizations, which can use their relationships with others in the community to bring many different players to the table (Folke et al. 2005), are key to ensuring that projects like the $\mathrm{MC}$ connect with the different voices required to create realistic and inclusive scenarios (Box 2).

\section{Box 2: A Stakeholder's Perspective on the MC Project}

By Kees Vanderheyden and Geneviève Poirier-Ghys of the Centre de la Nature du Mont Saint-Hilaire

For 15 years the Centre de la Nature du Mont Saint-Hilaire (CN) has been working to raise public awareness of the importance and vulnerability of our natural heritage, focusing on Mont Saint Hilaire (MSH) as one of the few protected areas in the region. As part of this mission, and with a desire to secure the protection of $\mathrm{MSH}$ in the face of urban development, the $\mathrm{CN}$ has been involved in active dialogue and outreach activities with neighboring landowners about ways to protect their land and biodiversity. The hope is that this will provide a buffer around MSH as well as provide green corridors linking the mountain with other regional woodlands.

The MC project came as welcome news for the $\mathrm{CN}$ because it provided an ideal opportunity to deepen understanding about the many ES provided by green spaces, including MSH, and build support for ongoing protection of the mountain and the region $\mathrm{s}$ natural areas. The MC project provided not only information about ES, but also ecological data from regional parks and surrounding forest fragments, and practical tools to help local land managers predict the impacts of their decisions on ES. Researchers have provided maps and scenarios that clearly illustrated the potential consequences of planning decisions on the ES provided by local green spaces.

Also critical to our success was the presence of a dedicated communications officer for the $\mathrm{MC}$ project to manage engagement with stakeholders. Unfortunately, this role is rare in scientific projects but was absolutely essential for the success of our project. Understanding and navigating the landscape of different stakeholders, decision makers, nongovernmental 
organizations, unions, and public groups that is present across the study area was key to engaging these groups, building scenarios, and leveraging our project into current decision-making processes. These interactions continually informed our empirical, historical, preliminary modeling, and scenario-building exercises (Fig. 3). Without this ability to effectively engage with important stakeholders, the MC project would not have been as relevant or effective.

\section{CONCLUSIONS}

The MC project and its conceptual framework represent a significant advance in our understanding of how human actions alter ES provision at landscape scales across social-ecological systems. Understanding how landscape structure and connectivity can alter biodiversity, ecosystem processes, and ultimately, the provision of ES is critical to more accurately predict the consequences of land-use/land-cover change. However, the ultimate impact of this new knowledge depends on our ability to translate it into tools that managers, policy makers, and other actors can comprehend and use. The MC project's use of scenarios has been crucial to involve stakeholders in each step of the MC project and build a collaborative project in which stakeholders are as invested as the researchers. Ultimately, this has allowed us to better capture the social and institutional dynamics that are integral to the Montérégie's social-ecological systems. Although creating scenarios, and indeed creating entire scientific studies, in collaboration with stakeholders involves challenges not traditionally faced in many ecological studies, the benefits for understanding the results and the increased potential for applying this knowledge to resource management are substantial. We believe that this type of codesign is key to understanding how to manage landscapes and ecosystems for ES and biodiversity, and using this knowledge to create tools that can help build multifunctional and sustainable landscapes.

Responses to this article can be read online at: http://www.ecologyandsociety.org/issues/responses. $\mathrm{php} / 7927$

\section{Acknowledgments:}

We thank the numerous organizations and stakeholders that have partnered with the Montérégie Connection (MC) project, in particular the Centre de la Nature Mont Saint-Hilaire, the town of Mont Saint-Hilaire, and the many farmers of the region who let us use their fields and forests. Denis Bainville created the compelling illustrations of the scenarios. Numerous undergraduate field assistants provided essential help and support in the field and lab. The MC project is supported by an NSERC Strategic Project Grant to $E M B, A G, M J L$, and JMR; a grant from the Ouranos Consortium to $A G, E M B$, and $M J L$; and a grant from the Max Bell Foundation to MJL, AG, and EMB. Work with stakeholders and community engagement was supported by the Trottier Institute for Science and Public Policy. Fieldwork and modeling were supported by scholarships to postdoctoral researchers and graduate students by NSERC, FRQNT, the Québec Centre for Biodiversity Science, and the European Commission.

\section{LITERATURE CITED}

Anderson, B. J., P. R. Armsworth, F. Eigenbrod, C. D. Thomas, S. Gillings, A. Heinemeyer, D. B. Roy, and K. J. Gaston. 2009. Spatial covariance between biodiversity and other ecosystem service priorities. Journal of Applied Ecology 46(4):888-896. http:// dx.doi.org/10.1111/j.1365-2664.2009.01666.x

Andersson, E., S. Barthel, and K. Ahrné. 2007. Measuring socialecological dynamics behind the generation of ecosystem services. Ecological Applications 17(5):1267-1278. http://dx.doi. org/10.1890/06-1116.1

Balvanera, P., I. Siddique, L. Dee, A. Paquette, F. Isbell, A. Gonzalez, J. Byrnes, M. I. O'Connor, B. A. Hungate, and J. N. Griffin. 2014. Linking biodiversity and ecosystem services: current uncertainties and the necessary next steps. BioScience 64 (1):49-57. http://dx.doi.org/10.1093/biosci/bit003

Bélanger, L., and M. Grenier. 2002. Agriculture intensification and forest fragmentation in the St. Lawrence valley, Québec, Canada. Landscape Ecology 17:495-507. http://dx.doi.org/10.1023/ A:1021443929548

Bennett, E. M., S. R. Carpenter, G. D. Peterson, G. S. Cumming, M. Zurek, and P. Pingali. 2003. Why global scenarios need ecology. Frontiers in Ecology and the Environment 1(6):322-329. http://dx.doi.org/10.1890/1540-9295(2003)001[0322:wgsne]2.0.co;2

Biggs, R., M. Schlüter, D. Biggs, E. L. Bohensky, S. BurnSilver, G. Cundill, V. Dakos, T. M. Daw, L. S. Evans, K. Kotschy, A. M. Leitch, C. Meek, A. Quinlan, C. Raudsepp-Hearne, M. D. Robards, M. L. Schoon, L. Schultz, and P. C. West. 2012. Toward principles for enhancing the resilience of ecosystem services. Annual Review of Environment and Resources 37(1):421-448. http://dx.doi.org/10.1146/annurev-environ-051211-123836

Cardinale, B. J., J. E. Duffy, A. Gonzalez, D. U. Hooper, C. Perrings, P. Venail, A. Narwani, G. M. Mace, D. Tilman, D. A. Wardle, A. P. Kinzig, G. C. Daily, M. Loreau, J. B. Grace, A. Larigauderie, D. S. Srivastava, and S. Naeem. 2012. Biodiversity loss and its impact on humanity. Nature 486:59-67. http://dx.doi. org/10.1038/nature11148

Carpenter, S. R., H. A. Mooney, J. Agard, D. Capistrano, R. S. DeFries, S. Diaz, T. Dietz, A. K. Duraiappah, A. Oteng-Yeboah, H. M. Pereira, C. Perrings, W. V. Reid, J. Sarukhan, R. J. Scholes, and A. Whyte. 2009. Science for managing ecosystem services: beyond the Millennium Ecosystem Assessment. Proceedings of the National Academy of Sciences of the United States of America 106(5):1305-1312. http://dx.doi.org/10.1073/pnas.0808772106

Chaplin-Kramer, R., M. E. O'Rourke, E. J. Blitzer, and C. Kremen. 2011. A meta-analysis of crop pest and natural enemy response to landscape complexity. Ecology Letters 14(9):922-932. http://dx.doi.org/10.1111/j.1461-0248.2011.01642.x

Chaplin-Kramer, R., R. P. Sharp, L. Mandle, S. Sim, J. Johnson, I. Butnar, L. Milà i Canals, B. A. Eichelberger, I. Ramler, C. Mueller, N. McLachlan, A. Yousefi, H. King, and P. M. Kareiva. 2015. Spatial patterns of agricultural expansion determine 
impacts on biodiversity and carbon storage. Proceedings of the National Academy of Sciences of the United States of America 112(24):7402-7407. http://dx.doi.org/10.1073/pnas.1406485112

Cowling, R. M., B. N. Egoh, A. T. Knight, P. J. O'Farrell, B. Reyers, M. Rouget, D. J. Roux, A. Welz, and A. WilhelmRechman. 2008. An operational model for mainstreaming ecosystem services for implementation. Proceedings of the National Academy of Sciences of the United States of America 105(28):9483-9488. http://dx.doi.org/10.1073/pnas.0706559105

Daily, G. C., S. Polasky, J. Goldstein, P. M. Kareiva, H. A. Mooney, L. Pejchar, T. H. Ricketts, J. Salzman, and R. Shallenberger. 2009. Ecosystem services in decision making: time to deliver. Frontiers in Ecology and the Environment 7(1):21-28. http://dx.doi.org/10.1890/080025

Diaz, S., F. Quétier, D. M. Cáceres, S. F. Trainor, N. PérezHarguindeguy, M. Syndonia Bret-Harte, B. Finegan, M. PeñaClaros, and L. Poorter. 2011. Linking functional diversity and social actor strategies in a framework for interdisciplinary analysis of nature's benefits to society. Proceedings of the National Academy of Sciences of the United States of America 108 (3):895-902. http://dx.doi.org/10.1073/pnas.1017993108

Dietz, T. 2013. Bringing values and deliberation to science communication. Proceedings of the National Academy of Sciences of the United States of America 110(S3):14081-14087. http://dx. doi.org/10.1073/pnas.1212740110

Dupras, J., and M. Alam. 2014. Urban sprawl and ecosystem services: a half century perspective in the Montreal area (Quebec, Canada). Journal of Environmental Policy \& Planning 17 (2):180-200. http://dx.doi.org/10.1080/1523908x.2014.927755

Eigenbrod, F., P. R. Armsworth, B. J. Anderson, A. Heinemeyer, S. Gillings, D. B. Roy, C. D. Thomas, and K. J. Gaston. 2010. Error propagation associated with benefits transfer-based mapping of ecosystem services. Biological Conservation 143 (11):2487-2493. http://dx.doi.org/10.1016/j.biocon.2010.06.015

Eigenbrod, F., V. A. Bell, H. N. Davies, A. Heinemeyer, P. R. Armsworth, and K. J. Gaston. 2011. The impact of projected increases in urbanization on ecosystem services. Proceedings of the Royal Society of London B: Biological Sciences 278 (1722):3201-3208. http://dx.doi.org/10.1098/rspb.2010.2754

Fahrig, L. 2003. Effects of habitat fragmentation on biodiversity. Annual Review of Ecology, Evolution, and Systematics 34:487-515. http://dx.doi.org/10.1146/annurev.ecolsys.34.011802.132419

Fahrig, L., J. Baudry, L. Brotons, F. G. Burel, T. O. Crist, R. J. Fuller, C. Sirami, G. M. Siriwardena, and J.-L. Martin. 2011. Functional landscape heterogeneity and animal biodiversity in agricultural landscapes. Ecology Letters 14(2):101-112. http://dx. doi.org/10.1111/j.1461-0248.2010.01559.X

Feininger, T., and A. K. Goodacre. 1995. The eight classical Montérégian hills at depth and the mechanism of intrusion. Canadian Journal of Earth Sciences 32:1350-1364. http://dx.doi. org/10.1139/e95-109

Flinn, K. M., and M. Vellend. 2005. Recovery of forest plant communities in post-agricultural landscapes. Frontiers in Ecology and the Environment 3(5):243-250. http://dx.doi.org/10.1890/1540-9295 (2005)003[0243:rofpci]2.0.co;2
Foley, J. A., R. S. DeFries, G. P. Asner, C. Barford, G. Bonan, S. R. Carpenter, F. S. Chapin, M. T. Coe, G. C. Daily, H. K. Gibbs, J. H. Helkowski, T. Holloway, E. A. Howard, C. J. Kucharik, C. Monfreda, J. A. Patz, I. C. Prentice, N. Ramankutty, and P. K. Snyder. 2005. Global consequences of land use. Science 309 (5734):570-574. http://dx.doi.org/10.1126/science.1111772

Folke, C., T. Hahn, P. Olsson, and J. Norberg. 2005. Adaptive governance of social-ecological systems. Annual Review of Environmental Resources 30:441-473. http://dx.doi.org/10.1146/ annurev.energy.30.050504.144511

Gonzalez, A., N. Mouquet, and M. Loreau. 2009. Biodiversity as spatial insurance: the effects of habitat fragmentation and dispersal on ecosystem functioning. Pages 134-146 in S. Naeem, D. E. Bunker, A. Hector, M. Loreau, and C. Perrings, editors. Biodiversity, ecosystem functioning, and human wellbeing: an ecological and economic perspective. Oxford University Press, Oxford, UK. http://dx.doi.org/10.1093/acprof:oso/97801995479$\underline{51.003 .0010}$

Gonzalez, A., B. Rayfield, and Z. Lindo. 2011. The disentangled bank: how loss of habitat fragments and disassembles ecological networks. American Journal Of Botany 98(3):503-516. http://dx. doi.org/10.3732/ajb.1000424

Gordon, L. J., G. D. Peterson, and E. M. Bennett. 2008. Agricultural modifications of hydrological flows create ecological surprises. Trends in Ecology \& Evolution 23(4):211-219. http://dx. doi.org/10.1016/j.tree.2007.11.011

Haddad, N. M., L. A. Brudvig, J. Clobert, K. F. Davies, A. Gonzalez, R. D. Holt, T. E. Lovejoy, J. O. Sexton, M. P. Austin, C. D. Collins, W. M. Cook, E. I. Damschen, R. M. Ewers, B. L. Foster, C. N. Jenkins, A. J. King, W. F. Laurance, D. J. Levey, C. R. Margules, B. A. Melbourne, A. O. Nicholls, J. L. Orrock, D.X. Song, and J. R. Townshend. 2015. Habitat fragmentation and its lasting impact on Earth's ecosystems. Science Advances 1: e1500052. http://dx.doi.org/10.1126/sciadv.1500052

Hanski, I. 2005. Landscape fragmentation, biodiversity loss and the societal response. EMBO Reports 6(5):388-392. http://dx.doi. org/10.1038/sj.embor.7400398

Hermy, M., and K. Verheyen. 2007. Legacies of the past in the present-day forest biodiversity: a review of past land-use effects on forest plant species composition and diversity. Ecological Research 22:361-371. http://dx.doi.org/10.1007/s11284-007-0354-3

Hoehn, P., T. Tscharntke, J. M. Tylianakis, and I. SteffanDewenter. 2008. Functional group diversity of bee pollinators increases crop yield. Proceedings of the Royal Society of London B: Biological Sciences 275(1648):2283-2291. http://dx.doi. org/10.1098/rspb.2008.0405

Holland, R. A., F. Eigenbrod, P. R. Armsworth, B. J. Anderson, C. D. Thomas, A. Heinemeyer, S. Gillings, D. B. Roy, and K. J. Gaston. 2011. Spatial covariation between freshwater and terrestrial ecosystem services. Ecological Applications 21 (6):2034-2048. http://dx.doi.org/10.1890/09-2195.1

Institut de la statistique du Québec (ISQ). 2014. Perspectives démographiques du Québec et des régions, 2011-2061. ISQ, Québec, Québec, Canada. 
Isbell, F., V. Calcagno, A. Hector, J. Connolly, W. S. Harpole, P. B. Reich, M. Sherer-Lorenzen, B. Schmid, D. Tilman, J. van Ruijven, A. Weigelt, B. J. Wilsey, E. S. Zavaleta, and M. Loreau. 2011. High plant diversity is needed to maintain ecosystem services. Nature 477(7363):199-202. http://dx.doi.org/10.1038/ nature 10282

Jobin, B., C. Latendresse, M. Grenier, C. Maisonneuve, and A. Sebbane. 2010. Recent landscape change at the ecoregion scale in Southern Québec (Canada), 1993-2001. Environmental Monitoring and Assessment 164(1):631-647. http://dx.doi.org/10.1007/ $\underline{\text { s10661-009-0918-5 }}$

Kremen, C., and R. S. Ostfeld. 2005. A call to ecologists: measuring, analyzing, and managing ecosystem services. Frontiers in Ecology and the Environment 3(10):540-548. http://dx. doi.org/10.1890/1540-9295(2005)003[0540:actema]2.0.co;2

Kremen, C., N. M. Williams, M. A. Aizen, B. Gemmill-Herren, G. LeBuhn, R. Minckley, L. Packer, S. G. Potts, T. Roulston, I. Steffan-Dewenter, D. P. Vázquez, R. Winfree, L. Adams, E. E. Crone, S. S. Greenleaf, T. H. Keitt, A. M. Klein, J. Regetz, and T. H. Ricketts. 2007. Pollination and other ecosystem services produced by mobile organisms: a conceptual framework for the effects of land-use change. Ecology Letters 10(4):299-314. http:// dx.doi.org/10.1111/j.1461-0248.2007.01018.x

Lamarque, P., A. Artaux, C. Barnaud, L. Dobremez, B. Nettier, and S. Lavorel. 2013. Taking into account farmers decision making to map fine-scale land management adaptation to climate and socio-economic scenarios. Landscape and Urban Planning 119:147-157. http://dx.doi.org/10.1016/j.landurbplan.2013.07.012

Larouche, M. 2013. Effects of past land use and landscape context on plant species composition and richness in woodlots of an agricultural landscape in Québec. Thesis. McGill University, Montreal, Québec, Canada.

Lautenbach, S., R. Seppelt, J. Liebscher, and C. F. Dormann. 2012. Spatial and temporal trends of global pollination benefit. PLoS One 7(4):e35954. http://dx.doi.org/10.1371/journal. pone.0035954

Letourneau, D. K., J. A. Jedlicka, S. G. Bothwell, and C. R. Moreno. 2009. Effects of natural enemy biodiversity on the suppression of arthropod herbivores in terrestrial ecosystems. Annual Review of Ecology, Evolution, and Systematics 40:573-592. http://dx.doi.org/10.1146/annurev.ecolsys.110308.120320

Likens, G. E. 2010. The role of science in decision making: does evidence-based science drive environmental policy? Frontiers in Ecology and the Environment 8(6):E1-E9. http://dx.doi. org/10.1890/090132

Millennium Assessment (MA). 2005. Ecosystems and human wellbeing: synthesis. Island Press, Washington, D.C., USA.

MacDonald, G. K., and E. M. Bennett. 2009. Phosphorus accumulation in Saint Lawrence River watershed soils: a centurylong perspective. Ecosystems 12(4):621-635. http://dx.doi. org/10.1007/s10021-009-9246-4

Maguire, D. Y., T. Nicole, C. M. Buddle, and E. M. Bennett. 2015. Effect of fragmentation on predation pressure of insect herbivores in a north temperate deciduous forest ecosystem. Ecological Entomology 40(2):182-186. http://dx.doi.org/10.1111/een.12166
Martins, K. T., A. Gonzalez, and M. J. Lechowicz. 2015. Pollination services are mediated by bee functional diversity and landscape context. Agriculture, Ecosystems \& Environment 200:12-20. http://dx.doi.org/10.1016/j.agee.2014.10.018

Mitchell, M. G. E., E. M. Bennett, and A. Gonzalez. 2013. Linking landscape connectivity and ecosystem service provision: current knowledge and research gaps. Ecosystems 16(5):894-908. http://dx.doi.org/10.1007/s10021-013-9647-2

Mitchell, M. G. E., E. M. Bennett, and A. Gonzalez. $2014 a$. Agricultural landscape structure affects arthropod diversity and arthropod-derived ecosystem services. Agriculture, Ecosystems \& Environment 192:144-151. http://dx.doi.org/10.1016/j.agee.2014.04.015

Mitchell, M. G. E., E. M. Bennett, and A. Gonzalez. 2014b. Forest fragments modulate the provision of multiple ecosystem services. Journal of Applied Ecology 51(4):909-918. http://dx.doi. org/10.1111/1365-2664.12241

Mitchell, M. G. E., A. F. Suarez-Castro, M. Martinez-Harms, M. Maron, C. McAlpine, K. J. Gaston, K. Johansen, and J. R. Rhodes. 2015. Reframing landscape fragmentation's effects on ecosystem services. Trends in Ecology \& Evolution 30(4):190-198. http://dx.doi.org/10.1016/j.tree.2015.01.011

Municipalité Régionale Comté de La Vallée-du-Richelieu (MRCVR). 2007. Schéma d'aménagement. MRC-VR, McMasterville, Québec, Canada. [online] URL: http://www.mrcvr.ca/ territoire amenagement.php?menu2 $=2$

National Research Council of the National Academies. 2004. Valuing ecosystem services: toward better environmental decisionmaking. National Academies Press, Washington, D.C., USA.

Peterson, G. D., T. D. Beard, Jr., B. E. Beisner, E. M. Bennett, S. R. Carpenter, G. S. Cumming, C. L. Dent, and T. D. Havlicek. $2003 \mathrm{~b}$. Assessing future ecosystem services: a case study of the Northern Highlands Lake District, Wisconsin. Conservation Ecology 7(3):1. [online] URL: http://www.consecol.org/vol7/iss3/ art1/

Peterson, G. D., G. S. Cumming, and S. R. Carpenter. $2003 a$. Scenario planning: a tool for conservation in an uncertain world. Conservation Biology 17(2):358-366. http://dx.doi.org/10.1046/ j.1523-1739.2003.01491.x

Phalan, B., M. Onial, A. Balmford, and R. E. Green. 2011. Reconciling food production and biodiversity conservation: land sharing and land sparing compared. Science 333:1289-1291. http://dx.doi.org/10.1126/science.1208742

Ramankutty, N., A. T. Evan, C. Monfreda, and J. A. Foley. 2008. Farming the planet: 1. Geographic distribution of global agricultural lands in the year 2000. Global Biogeochemical Cycles 22(1):GB1003. http://dx.doi.org/10.1029/2007GB002952

Raudsepp-Hearne, C., G. D. Peterson, and E. M. Bennett. 2010. Ecosystem service bundles for analyzing tradeoffs in diverse landscapes. Proceedings of the National Academy of Sciences of the United States of America 107(11):5242-5247. http://dx.doi. org/10.1073/pnas.0907284107

Renard, D., J. M. Rhemtulla, and E. M. Bennett. 2015. Historical dynamics in ecosystem service bundles. Proceedings of the National Academy of Sciences of the United States of America 112:13411-13416. http://dx.doi.org/10.1073/pnas. 1502565112 
Ricketts, T. H., J. Regetz, I. Steffan-Dewenter, S. A. Cunningham, C. Kremen, A. Bogdanski, B. Gemmill-Herren, S. S. Greenleaf, A. M. Klein, M. M. Mayfield, L. A. Morandin, A. Ochieng, and B. F. Viana. 2008. Landscape effects on crop pollination services: are there general patterns? Ecology Letters 11(5):499-515. http:// dx.doi.org/10.1111/j.1461-0248.2008.01157.x

Seiferling, I., R. Proulx, and C. Wirth. 2014. Disentangling the environmental-heterogeneity-species-diversity relationship along a gradient of human footprint. Ecology 95(8):2084-2095. http:// dx.doi.org/10.1890/13-1344.1

Swetnam, T. W., C. D. Allen, and J. L. Betancourt. 1999. Applied historical ecology: using the past to manage for the future. Ecological Applications 9(4):1189-1206. http://dx.doi. org/10.1890/1051-0761(1999)009[1189:aheutp]2.0.co;2

Tardif, B., G. Lavoie, and Y. Lachance. 2005. Atlas de la biodiversité du Québec-les espèces menacées ou vulnerables. Gouvernement du Québec, Ministère du Développement Durable, de l'Environnement et des Parcs, Québec, Québec, Canada.

Terrado, M., R. Tauler, and E. M. Bennett. 2014. Landscape and local factors influence water purification in the Monteregian agroecosystem in Québec, Canada. Regional Environmental Change. 1-13. http://dx.doi.org/10.1007/s10113-014-0733-6

Van der Heijden, K. 2005. Scenarios: the art of strategic conversation Second edition. John Wiley \& Sons, Hoboken, New Jersey, USA.

Vellend, M., K. Verheyen, K. M. Flinn, H. Jacquemyn, A. Kolb, H. Van Calster, G. Peterken, B. J. Graae, J. Bellemare, O. Honnay, J. Brunet, M. Wulf, F. Gerhardt, and M. Hermy. 2007. Homogenization of forest plant communities and weakening of species-environment relationships via agricultural land use. Journal of Ecology 95(3):565-573. http://dx.doi.org/10.1111/ j.1365-2745.2007.01233.x

Wollenberg, E., D. Edmunds, and L. Buck. 2000. Using scenarios to make decisions about the future: anticipatory learning for the adaptive co-management of community forests. Landscape and Urban Planning 47(1):65-77. http://dx.doi.org/10.1016/s0169-2046 (99)00071-7

Ziter, C., E. M. Bennett, and A. Gonzalez. 2013. Functional diversity and management mediate aboveground carbon stocks in small forest fragments. Ecosphere 4(7):art85. http://dx.doi. org/10.1890/ES13-00135.1

Ziter, C., E. M. Bennett, and A. Gonzalez. 2014. Temperate forest fragments maintain aboveground carbon stocks out to the forest edge despite changes in community composition. Oecologia 176 (3):893-902. http://dx.doi.org/10.1007/s00442-014-3061-0 